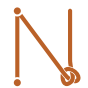

Volumen $6 \mathrm{~N} .{ }^{\circ} 45$

julio - diciembre de 2018

ISSN: 0122-4328

ISSN-E: 2619-6069

pp. 104-115

\title{
Ser maestro no vale la pena, vale la vida
}

\author{
Being a Teacher Isn't \\ Worth the Trouble, \\ it's Worth One's Life
}

Ser profesor ñao vale a pena, vale a vida

\author{
Leydi Johana Ramírez Sánchez* \\ Lina Fernanda Mahecha Morales* \\ Luisa Fernanda Forero Vergara" \\ Cindy Natalia Bueno Ostos
}

Fecha de recepción: 29-10-18

Fecha de aprobación: 30-10-18

\section{PARA CITAR ESTE ARTÍCULO}

Ramírez, L., Mahecha, L., Forero, L., y Bueno, C. (2018). Ser maestro no vale la pena, vale la vida. Nodos y nudos, 6(45), 104-115. doi: 10.17227/nyn.vol6.num45-8634
Aspirante a título de Licenciada en Educación Infantil, Universidad Pedagógica Nacional. Estudiante investigadora Semillero de Educaciones Rurales. lei_ljramirezs154@pedagogica.edu.co

* Aspirante a título de Licenciada en Educación Infantil, Universidad Pedagógica Nacional. Estudiante investigadora Semillero de Educaciones Rurales.

lei_Ifmahecham012@pedagogica.edu.co

... Aspirante a título de Licenciada en Educación Infantil, Universidad Pedagógica Nacional. Estudiante investigadora Semillero de Educaciones Rurales. lei_Ifforerov612@pedagogica.edu.co

Aspirante a título de Licenciada en Educación Infantil, Universidad Pedagógica Nacional. Estudiante investigadora Semillero de Educaciones Rurales. lei_cnbuenoo179@pedagogica.edu.co 


\section{RESUMEN}

A partir de la búsqueda por visibilizar la labor de los maestros rurales en Colombia, en el presente artículo se da cuenta de la constante lucha que ellos llevan. El trabajo está organizado en cuatro apartados, cada uno de estos profundizan en la historia de vida de una maestra de Arauca, que da testimonio de las realidades en las que se han visto inmersos los maestros durante los últimos veinte años y cómo estas han impactado en su vida personal. Entre dichas realidades, se destacan: el conflicto armado, social, económico y político; desde estos apartados se hace una reflexión en torno a los retos educativos y sociales que trae consigo la profesión docente, siendo esta la esperanza viva que permite trabajar arduamente por los sueños de cada uno de los sujetos que habitan en la escuela.

Palabras clave: maestro rural; conflicto; educación; territorio

\section{ABSTRACT}

From the search to make visible the work of rural teachers in Colombia, in the present article, the constant struggle they have is shown. The work is organized into four sections, each of which delves into the life story of a teacher from Arauca, who gives testimony of the realities in which teachers have been immersed during the last twenty years and how these have impacted in her personal life. Among these realities, it stands out: the armed, social, economic and political conflict; From these sections, there is a reflection on the educational and social challenges that the teaching profession brings, this being the living hope that allows to work hard for the dreams of each one of the subjects that live in the school.

Keywords: rural teacher; conflict; education; territory

\section{RESUMO}

Partindo da busca para tornar visivel o trabalho dos professores rurais na Colômbia, no presente artigo de reflexão a luta constante que eles têm é apresentada. 0 trabalho é organizado em quatro seções, cada uma das quais aprofunda a história de vida de um professor de Arauca, que dá testemunho das realidades em que os professores foram imersos durante os últimos vinte anos e como elas impactaram sua vida pessoal. Entre essas realidades, destacase: o conflito armado, social, econômico e político; destas seções há uma reflexão sobre os desafios educacionais e sociais que a profissão docente traz, sendo esta a esperança viva que permite trabalhar muito pelos sonhos de cada um dos sujeitos que moram na escola.

Palavras-chave: professor rural; conflito; educação; território 


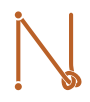

Volumen $6 \mathrm{~N} .{ }^{\circ} 45$

julio - diciembre de 2018

ISSN: 0122-4328

ISSN-E: 2619-6069

pp. 104-115
En Colombia la mayor parte del territorio es rural, según el Ministerio de Cultura (s.f.) en el censo realizado por el Departamento Administrativo Nacional de Estadistica (Dane) (2005), "solo el $25 \%$ de la población vive alli", el porcentaje restante está concentrado en las ciudades, lo que genera una preocupación por la población citadina, invisibilizando la ruralidad. Por consiguiente, en cuanto a su educación, dicho descuido está presente en los curriculos de algunas universidades, un claro ejemplo de ello es esta maestra, que siendo formada en una universidad cercana a la ruralidad no tuvo acercamiento previo a la experiencia de la escuela unitaria y multigrado. Al respecto, Lara, Rincón, Hernández y Zamora (2012) mencionan:

[...] con raras excepciones, los maestros y maestras rurales colombianos no han recibido una orientación especifica que contribuya a su cualificación para su desempeño en estos ambientes. En otras palabras, el contexto, escenario o dimensión rural de la educación es invisible para casi todas las instituciones formadoras de educadores, tanto las Escuelas Normales Superiores como (especialmente) las Facultades de Educación del país. (p. 26).
Este artículo surge en el marco de la visita realizada a Arauca durante el espacio académico Educación Rural en Colombia, un escenario donde se visibilizan las labores de los maestros rurales y su papel en la educación de nuestro país.

Habiamos esperado este viaje durante varias semanas, la emoción por conocer las tierras del alcaraván y la hallaca nunca faltaron, las clases previas al viaje fueron muy productivas, con conversaciones sobre nuestra tarea en la anhelada visita a Arauca.

La alegría nos consumía y las ganas de llegar eran enormes; lejos de imaginar que nos esperaban 15 horas de viaje, dejamos a un lado todo afán y disfrutamos del camino, la comida, las personas, el paisaje, los animales y todo eso lindo que trae el viajar y conocer nuevas tierras. Llegaba la noche y el cansancio empezaba a aparecer, los rayos y truenos eran protagonistas en la tormenta que acompañaba la cálida noche en los Llanos Orientales de nuestra querida Colombia. De repente, alguien dijo: "Llegamos a Tame". Era muy tarde y el viaje en carretera no podía continuar por cuestiones de seguridad, una vez nos instalamos decidimos dejar todo listo para cumplir con nuestro objetivo, conocer y visibilizar la labor del maestro rural desde sus historias de vida en la escuela.

Entre las distintas experiencias en este viaje tuvimos la oportunidad de conocer a maestros y maestras apasionados por su quehacer, conscientes de la importancia que ha tenido para las comunidades rurales de Arauca, su papel como sujeto político en la época de conflicto y posacuerdo por la que atraviesa Colombia, entre estos maestros queremos destacar la historia de Marta Suárez, licenciada en Educación Física, Recreación y Deportes de la Universidad de Pamplona, y maestra en ejercicio desde 1997, quien nos contó su historia de vida.

Maestros y maestras como Marta abundan en Colombia, su labor les ha permitido vivenciar el conflicto por el que ha atravesado nuestro pais en las últimas décadas, y acompañar a sus estudiantes en la constante lucha por resolver los retos que esta dinámica les pone en frente.

De su experiencia como maestra rural se rescatan cuatro hitos, que serán abordados a continuación.

\section{El llamado}

¿Qué me motivó a ser docente? Primero, la necesidad de un trabajo, salir de la universidad, desubicada buscando trabajo de mi perfil, de mi carrera que era en lo que mejor me desempeñaba, tenía una amiga acá en el departamento de Arauca, la cual pues me invitó a conocer y me vine; soy de Pamplona, gracias a Dios llegué a una urbanización de docentes en la Esmeralda, yo recién graduadita, un profesor me mandó a una escuela unitaria y pues me dejó sola, yo no sabía ni qué hacer, entonces me acordé de todo lo que había visto en la universidad y pues ese día fue tenaz, porque uno queda... bueno, impactado, pues sí y uno puede practicar cosas, pero de mi carrera, no de todas las áreas porque allá en una escuela unitaria se orientan todas las áreas, entonces pues... es 
difícil, llegar uno así, sí, yo soy buena es para el deporte, a mí no me pongan a orientar otra área, y saber que tenía que hacerlo porque le estaba haciendo un favor al profe, entonces, asi empecé. Ya después, los profesores me fueron conociendo, empecé a hacer una licencia en el Colegio José María Carbonell a una profesora que se había accidentado en una moto, ella era la profesora de los grados sexto de matemáticas. jImagínese, yo licenciada en educación física y orientando matemáticas! Pero yo dije: "Yo necesito el trabajo", entonces hagámosle, orienté casi por medio año matemáticas en el grado sexto en el José Maria Carbonell, después ya me conocieron los docentes y segui fue por licencias amigables que empecé a trabajar en lo que es la docencia.

\section{Lo que nos hace maestros}

Mi formación, como ya les dije, Licenciatura en Educación Fisica, me hice una especialización como a los tres o cuatro años, también con la universidad de Pamplona en Entrenamiento Deportivo, porque esto es lo que a mí me apasiona, lo que me gusta, todo lo relacionado con el deporte, la recreación y quiero hacerme una maestría de acuerdo con mi perfil, pero no la he podido encontrar y si la he visto, es muy lejana de acá, no me favorece, entonces tengo que optar por otra maestría.

Mi recorrido, dígame, empecé a laborar en el 2003 en el colegio, después pase a la escuela y de ahí trabajé unos cuatro años, después me devolví a mi pueblo porque ya se había acabado el trabajo, estando alli en la casa me llamaron del departamento porque había dejado hojas de vida, pues porque las licencias eran amigables, usted trabajaba dos meses pero era posible que en tres o cuatros meses usted ya no tuviera trabajo o usted podia trabajar dos o tres días y no tener más trabajo, fue entonces que decidí irme para la casa, a ir a buscar otra opción y después como al mes recibi una llamada de aquí de la Secretaría de Educación Departamental: "Es que aquí tenemos su hoja de vida, la necesitamos para Filipinas". Yo pensé: "¿Y eso dónde queda?". Yo no conocía, me contestaron: "Ahí cerquita, en el caserío de Arauquita", y dije: "Ah, bueno. Pues si es cerquita, hagámosle". Listo, fui a Arauca y firmé, y dije: "¿Y ahora, dónde queda Filipinas?". Me respondieron: "Usted debe ir a buscarlo. Vaya y pregunte en el terminal. Allá debe coger un was que la lleve hasta allá". Un was es un carrito trochero, para la carretera destapada. Entonces fui y pregunté, y me dijeron: "El más cercano es el que sale en el otro pueblo que se llama Saravena, de ahí pasa a la Esmeralda y de la Esmeralda se va a Pueblo Nuevo, de Pueblo Nuevo agarra y se va para Filipinas". O sea que eso no es tan cerca como yo creía. Entonces dije: "Bueno". Quién sabe, en ese tiempo era zona de conflicto porque estaba la guerrilla y había mucha violencia, la violencia vivía en el departamento desde hace muchos años, ese día me tocó llevar acompañante, porque persona que era nueva tenía que llevar a alguien que lo recomendara porque si no, se sabe que la violencia optaba por matar, si no lo conocian a usted, entonces listo, lo mataban.
Es evidente cómo la violencia ha invadido cada rincón de este pais, controlando y determinando el actuar y sentir de cada colombiano; guerrillas, ejército, paramilitares y gobiernos corruptos han sido los principales actores de la gran crisis humanitaria que ha vivido Colombia en las últimas décadas, donde la escuela y los maestros se han visto totalmente afectados. De acuerdo con Restrepo (1999):

[...] la vida escolar tanto en el entorno rural como en el urbano, es escenario privilegiado de violaciones a las normas del Derecho Internacional Humanitario y de los Derechos Humanos por parte de los distintos actores del conflicto. Este hecho coloca a la escuela en varias regiones de pais frente a una situación de emergencia educativa y social que es necesario abordar integralmente. (p. 19). 


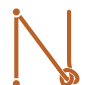

Volumen $6 \mathrm{~N} .{ }^{\circ} 45$ julio - diciembre de 2018 ISSN: 0122-4328 ISSN-E: 2619-6069 pp. $104-115$
Arauca históricamente ha sido uno de los departamentos más afectados por la guerra entre guerrillas y la fuerza pública. Su riqueza territorial ha sido el principal factor de dichas disputas; sus habitantes han tenido que presenciar múltiples dinámicas conflictivas, un claro ejemplo de ello es el relato de esta maestra, que hace énfasis en cómo debía sobrevivir en medio de los fuegos cruzados y las constantes amenazas a personas desconocidas para los altos mandos de la región.
Sali de ahí de la Esmeralda, me fui un domingo en la tarde para mirar el recorrido, claro me fui a la una de la tarde y llegué a Filipinas a las ocho de la noche. Entonces dije: "No es asi como tan cerquita, no es asi como tan fácil".

Empecé a trabajar, lo primero que tenía que hacer era quedarme allá en la escuela, en donde se quedan todos los docentes. Éramos siete mujeres y el director en ese tiempo era un hombre, siempre la vida social allá era dificil, un día uno se encontraba con la guerrilla, al otro día con el ejército, al otro día se encontraba con la otra guerrilla y así, uno tenía que estar con esa zozobra que en ese tiempo en cualquier momento se dieran plomo.

Empecé a trabajar alli, solamente había hasta quinto, era un profesor por grado y orientaba todas las áreas. Ese año me dieron el grado cuarto y pues esa es la experiencia que tuve en la escuela de la Esmeralda. Me ayudó muchísimo y ya allí trabajamos con las cartillas de Escuela Nueva, estas las utilizan para aligerar el proceso en las escuelas rurales, es una cartilla que trae actividades, trae temas y ahi usted va trabajando con los chicos y usted va orientando lo que está en la cartilla.

Siempre me tocaba adaptarme a todo eso, el agua allá no es potable, solamente salía un carro y era a cierta ahora, a las once de la mañana y no salían más carros y usted por una necesidad le tocaba de pronto que un habitante le hiciera el favor y lo sacara; a uno le cobraban el expreso. Bueno, listo estuve allá 8 meses trabajando, fue una experiencia chévere porque empecé a trabajar con jóvenes ya más grandes, mi trabajo se fue fortaleciendo a pesar de que no estaba en lo mío, yo sabía que me estaba gustando lo que estaba haciendo porque lo importante es saber que a uno le guste lo que está haciendo, alli nos empezamos a preparar con los profesores y profesoras en las tardes para presentarnos al concurso para la docencia, todas estudiábamos allá, bueno fue el momento del concurso, eso fue en diciembre y gracias a Dios, de las siete mujeres que estudiamos, yo pasé, fui la única que pasé, de ahí me favoreció ese concurso porque me pude acercar más a donde yo vivía que era la Esmeralda. Me permitieron escoger una plaza más cercana y ahi escogí cuatro esquinas que queda a veinte minutos de aquí, esa escuela es sede de acá de la Institución Educativa Andrés Bello entonces me vine. En 2006 llegué aquí, trabajamos dos docentes, nos repartíamos los grados, yo orienté desde preescolar hasta tercero y el otro profe orientaba cuarto y quinto que eran los más grandecitos, fue una gran experiencia donde yo ya cogí cancha porque ya había trabajado en la escuela de Filipinas y alli me quedé. Era un trabajo fuerte pues trabajar con varios grados en todas las áreas es un trabajo tenaz, pero es muy gratificante por los niños, yo tengo niños ahorita en este colegio que les orienté clase en preescolar y primero y ya ahorita ya están en décimo y once. Entonces uno mira y piensa; "Yo le enseñé a este chico a leer", "les enseñe a multiplicar", y así y uno se siente feliz. Esas son experiencias que a uno le hacen coger amor a la profesión. Ya después llegué a Cuatro Esquinas, allí duré dos años. El profesor que era director de acá del colegio me dijo que necesitaba una licenciada en Educación Física y que me viniera para acá, entonces yo le dije que yo estaba muy amañada en la escuela porque 


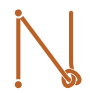

Volumen $6 \mathrm{~N} .{ }^{\circ} 45$ julio - diciembre de 2018 ISSN: 0122-4328 ISSN-E: 2619-6069 pp. $104-115$
Cuando la profesora Martha encuentra en su camino la escuela unitaria expresa que es "un trabajo fuerte, pues trabajar con varios grados en todas las áreas es un trabajo tenaz, pero es muy gratificante por los niños":

La manera como estos maestros viven la escuela del campo [...] por un lado, sentimientos de tristeza y de soledad por las desigualdades sociales y sus consecuencias sobre la vida de las escuelas y de las poblaciones con las cuales trabajan; al mismo tiempo, cada historia de vida expresa la vitalidad y la decisión con que estos maestros enfrentan las adversidades, piensan, construyen y reconstruyen constantemente la escuela campesina. (Loaiza, 2016, p. 91).

Entender al maestro rural implica reconocer el contexto, las dinámicas que alli se presentan, las relaciones que se tejen con la tierra... los niños a pesar de que tenían ahí sus indisciplinas ellos le aportan a uno mucho cariño y uno les coge cariño a ellos, entonces yo le decía que no.

Al profe con el que yo estaba allá en la escuela le dije que me iba a venir, entonces él me dijo: "No, no, no. Entonces si usted se va, yo me voy". Pero no, a los niños allá no los podíamos dejar solos. Entonces le dije: "Espere, al que le salga más rápido ese traslado se va", y a mí me salió rápido, entonces me vine y por eso estoy acá en el Andrés Bello desde el 2008 y ya cuando llegué, no llegué a orientar educación física sino llegué a orientar en el grado tercero; luego en 2009 ya se acomodó el horario, acá ya entró lo que era la telesecundaria entonces ya se tenía sexto y séptimo, por eso ya pude orientar educación física en bachillerato, y en la primaria

\section{Superando retos}

Desde hace un tiempito para acá el reto es quedarme en la docencia porque hay cosas que por el pasar del tiempo, como que yo no sé, le impacta a uno en la vida, sobre todo en la vida personal, sí. Entonces en estos últimos dos años me he querido retirar de la docencia, mi reto es quedarme aquí, cogerle amor a este trabajo, cogerle amor a mis estudiantes, saber que esto que estoy haciendo, de verdad llene mi vida personal. Y no sé si lo pueda cumplir, porque hay momentos en que digo: "iYa no más!, me voy, yo ya otra cosa haré.. Uno en la educación física se puede desempeñar digo yo, por allá voy y monto una escuela de fútbol, monto una escuela de baloncesto, algo haré, pero hay momentos en que todavía tengo ese reto, el reto de saber que en algún momento voy a decir que no; esto ya es lo mío y aquí me voy a quedar.

\section{Maestro rural, valor y vocación}

Esta mañana hablábamos con algunos de sus compañeros sobre la importancia del maestro, no solo aqui en el campo sino también en la ciudad, pero resaltamos por lo menos el profesor que trabaja en lo rural porque es la persona que los estudiantes ven como la persona que sabe, la persona que les va a enseñar a ellos a ser personas de bien, por lo menos ellos lo ven a uno como la persona adulta, como la persona importante y no solo para los estudiantes, sino también para los padres de familia. Para la comunidad, nosotros decimos que si este pueblo no tuviera este colegio, sería un pueblo fantasma, porque cuando estamos en semana en el pueblo, el ruido de los estudiantes se siente y se sabe que está vivo, pero de pronto usted viene un día que no haya clase y este pueblo es fantasma, es en silencio, no hay ruido, entonces es el alma. ¿Qué pasaría si en este colegio no hubieran maestros? Pues yo creo que sería algo desolador, entonces es algo importante para la vida de la comunidad que hayan maestros. Les decía a sus compañeros que a los estudiantes no les tenemos que decir que se vayan del campo, debemos decirles que el campo hay que quererlo, que el campo es el sustento de ellos, no les podemos decir: "Miren chicos, ustedes en la ciudad van a encontrar vida", no, porque eso es mentira, pero ellos tienen visiones porque la televisión y el internet les muestran cómo los seres humanos entramos al consumismo. Los chicos ya 
con internet y todas esas cosas creen que la sociedad les brinda algo mejor. Ellos quieren irse del campo y no todo es desacierto en el campo. Debemos decirles que el campo es lo que nos genera el sustento, la vida, que hay que ir a estudiar pero hay que regresar al campo para que esos conocimientos los fortalezcan acá y sean ellos los formadores de sus hijos. Es por eso que es importante el maestro en la parte rural.

Marta Suarez, profesora de la Institución Andrés Bello, Arauca (Meta).

Su relato es contundente. El Ilamado que la convirtió en maestra rural fue inesperado, sin embargo, este no fue un inconveniente; impulsada por la necesidad y el amor a su profesión, dijo si a un camino que pocos deciden emprender: la educación rural.

Conocer los primeros pasos de Marta nos llenó de sorpresa, cada detalle que relata da cuenta del amor que tiene a su profesión; ir a sus inicios es un mínimo acercamiento a la realidad que a diario viven muchos maestros rurales; escuchar de cerca su testimonio permite corroborar que esta labor educativa está siempre sujeta a cambios, que construyen la experiencia como maestros. Un día puede tornarse idilica y llena de sueños y al siguiente ser enfrentada a una situación que requiera de toda la atención y voluntad, como lo fue para la maestra enfrentarse al reto de la escuela unitaria sin conocer bien cómo funcionaba.

Cada una de las pruebas que la vida brinda a esta profesión nos hacen más humanos, más cercanos a la comunidad, a los niños y niñas, a las familias; pero, sobre todo, van forjando el carácter y formando experiencialmente nuestra profesión.

La presencia de los maestros y maestras es fundamental, sirven de mediadores y protectores, en especial de los niños y niñas que se encuentran en condición de vulnerabilidad, demostrando que la labor del maestro trasciende de lo académico a lo social, liderando procesos que permitan comunicar a la comunidad que:

Los y las docentes de las escuelas rurales deben ser más que maestros; han de trascender el quehacer del aula y visualizar la comunidad y sus necesidades como su campo de acción, ejercer procesos de liderazgo, diseñar proyectos que nazcan y que respondan a las necesidades de la comunidad, que promueva y que fortalezca procesos de educación no formal, que sea capaz de investigar y de hacer una lectura constante de la realidad de su aula y de su entorno, con el fin de que la entrega de la docencia sea pertinente y de calidad. (Ovares, Méndez, Torres y Cerdas, 2007, pp. 124-125).

Este ha sido el caso de Marta, quien siempre ha procurado ir más allá en su profesión, logrando así que su formación académica, profesional y personal haya sido nutrida por múltiples experiencias que le posibilitaron enfrentar con entereza los azares de la vida; el trabajo realizado con los estudiantes y con la comunidad ha hecho que su profesión obtenga un valor más significativo.
El gran reconocimiento que se le da al maestro en las escuelas rurales ha sido gracias a su arduo y constante trabajo con la comunidad, asi se convierte en un promotor de estrategias, propuestas y organizaciones, que logran llevarse a cabo porque "se piensan a sí mismos, con autonomía; son maestros que valoran su quehacer, como motor de sus propias vidas. Son maestros que expresan una gran pasión por lo que hacen día a dia en las escuelas campesinas" (Loaiza, 2016, p. 91). 


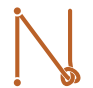

Volumen 6 N. ${ }^{\circ} 45$ julio - diciembre de 2018 ISSN: 0122-4328 ISSN-E: 2619-6069 pp. $104-115$
Sin embargo, su relato llama a la reflexión sobre la importancia de ampliar la cobertura y crear escenarios de formación para maestros y jóvenes más cercanos a los territorios, fortaleciendo los escenarios educativos y de capacitación, para así lograr que la población tenga la oportunidad de acceder a los diferentes niveles de educación.

Como maestras en formación resulta fundamental cuestionarse frente a los imaginarios educativos que construimos socialmente, de allí la importancia de este encuentro de saberes con maestros y maestras que hablan desde sus experiencias en el campo educativo y demuestran cómo la labor educativa está siempre en una constante construcción, rodeada de cambios y de logros que fortalecen la vocación del maestro.

El maestro rural es un sujeto arraigado a su territorio, es el ser que con su trabajo genera esperanza, amor y ganas de superar las adversidades. Escuchar a Marta hablar sobre sus temores y sentires permite visibilizar el amor que tiene hacia su profesión:

La experiencia moviliza en el maestro el deseo de saber y de transformar, porque a la vez que reconocen y analizan su quehacer, muchas veces experimentan una sensación de vacio, de insatisfacción, una necesidad de completud que también moviliza y activa su voluntad de acción. (Martínez, 2012, p. 7).

Esta maestra es un ejemplo de cómo el maestro rural lucha por construir un país con mejores condiciones de vida, trabajando desde su territorio, Arauca, una tierra llena de coraje, esperanza y sueños por cumplir, que cada día gracias al esfuerzo de maestros como ella logran darle vida y color a este espacio, motivando a los más jóvenes a quedarse en el campo y trabajar en pro de la comunidad y el territorio. Estas iniciativas se dan desde una constante reflexión sobre su práctica pedagógica; como menciona Marta, existen momentos en los que muchos quisieran desistir y tomar otros caminos, pero es su convicción y esperanza de cambio en la educación la que los mantiene en sus escuelas, creando propuestas que vinculen las particularidades de la comunidad y el territorio. Es necesario "entender la voz del maestro como fundamental en la construcción de conocimiento sobre la escuela campesina, dado que es este quien la vive y la siente, quien la construye día tras dia" (Loaiza, 2016, pp. 86-87). El maestro rural que decide continuar en este camino incide de manera significativa en la vida de sus estudiantes, incluso en la vida de la comunidad.

Estas experiencias enriquecen nuestra formación como futuras maestras. Tener un acercamiento a las diversas realidades de la educación en Colombia nos da la oportunidad de consolidar una visión más contextualizada de la labor que realizamos, nos brinda herramientas para el futuro cercano que estamos por afrontar y nos permite entender que la labor del maestro trasciende el aula, marca el territorio y fortalece la vida comunitaria.

Finalmente, hay que resaltar que los maestros rurales son importantes y respetados por la comunidad, se reconocen como sujetos políticos, trabajadores de la cultura que entregan todo por sus estudiantes, fortaleciendo la 
identidad campesina y el respeto por sus orígenes. Experiencias como estas se convierten en una voz de aliento, en una nueva oportunidad para entender que trabajar con la infancia requiere reconocer otros modos de estar, sentir y vivir el contexto, pues en ocasiones se torna complicado avanzar en los sueños, los temores se hacen más grandes, pero conocer historias como esta nos permite entender que aunque el camino sea difícil vale la vida entregarse en cuerpo y alma por cada uno de los seres que están en el aula, pues siempre será recompensado en sus sonrisas y logros.

\section{Referencias}

Lara, M., Rincón, A, Hernández, M. y Zamora, F. (2012). Abordajes en la formación de educadores para el ejercicio rural de la docencia. Bogotá: Códice.

Loaiza, Á. (2016). Acercamiento a las escuelas campesinas: entre voces de maestros. Revista Nodos y Nudos, 4(40), 85-94. Recuperado de http://revistas.pedagogica.edu. co/index.php/NYN/article/download/5249/4015/

Martínez, M. (2012). Redes, experiencias y movimientos pedagógicos. Revista de Ciencia y Tecnología, 14(18), pp. 5-11. Recuperado de http://www.scielo.org.ar/pdf/recyt/n18/n18a01.pdf

Ministerio de Cultura (s.f.). Población campesina y cultura. Recuperado de http:// www.mincultura.gov.co/prensa/noticias/Documents/Poblaciones/POBLACI\%C3\%93N\%20CAMPESINA\%20Y\%20CULTURA.pdf

Ovares, S., Méndez, N., Torres, N. y Cerdas, Y. (2007) La educación rural y sus desafíos en el siglo XXI. Revista Electrónica Educare, II, pp. 124-125. Recuperado de http:// www.revistas.una.ac.cr/index.php/EDUCARE/article/download/1382/1302/

Restrepo, M. (1999). Escuela y desplazamiento: una propuesta pedagógica. Bogotá: Ministerio de Educación Nacional. 


\section{Diálogo del conocimiento}

Este artículo narra la historia de vida de una maestra rural, los caminos recorridos, las realidades a las que se ve enfrentada en zonas alejadas y de conflicto armado, donde la incertidumbre y las búsquedas permanentes de enfrentar la educación rural la van configurando como maestra y como mujer.

El insumo principal de este artículo es la fuente viva de la maestra Marta, quien deja ver en su narración las construcciones de realidad que ha elaborado y que le dan sentido a su quehacer docente desde las experiencias del pasado. De igual forma, deja ver la mujer que sueña, que teje lazos de solidaridad en medio de la soledad, que teme, que lucha y que en ocasiones se siente frustrada. En este marco, la autora reconoce el valor del relato de vida como fuente fundamental para la reflexión y el análisis de las realidades de la educación rural en Colombia, y pone de relieve la experiencia académica desde la narración, como elemento principal para hacer lecturas asociadas al contexto social, político y cultural.

Otro elemento fundamental del artículo, y que seguramente sin proponérselo la autora nos muestra, es la incidencia de las salidas pedagógicas en la formación docente, la posibilidad de asistir a esos territorios donde las realidades sociales, las infancias y la escuela cobran otros significados, atravesados por las carencias, resultado del abandono estatal, pero también de las posibilidades que ofrece el entorno, las relaciones que se establecen, el lugar protagónico que ocupa la maestra o el maestro, y la escuela como posibilidad de restablecer el orden, como lugar que posibilita "el normal" transcurrir de los dias y la esperanza de la continuidad de la vida. Este reconocimiento de contextos, sujetos y encuentros con esas experiencias de vida, permiten a la maestra en formación repensar y resignificar su ser docente, las demandas que hacen regiones como el Arauca y la necesidad inaplazable de visibilizar y poner como prioridad en la agenda nacional la educación rural.

Por último, se resalta la importancia de los maestros que escriben sobre maestros, como posibilidad de interpelar, reflexionar y construir-nos en múltiples direcciones. Este artículo le permite, a la maestra rural, reconstruir y desde alli resinificar su historia como educadora; a la maestra en formación, comprender y ampliar los horizontes de sentido de la educación rural, y a los lectores, problematizar y seguir profundizando en la pregunta por los maestros rurales, las dinámicas establecidas y emergentes y el lugar de la escuela en zonas de conflicto armado.

Clara Esperanza Quinche López Universidad Pedagógica Nacional clara.quinche@gmail.com 


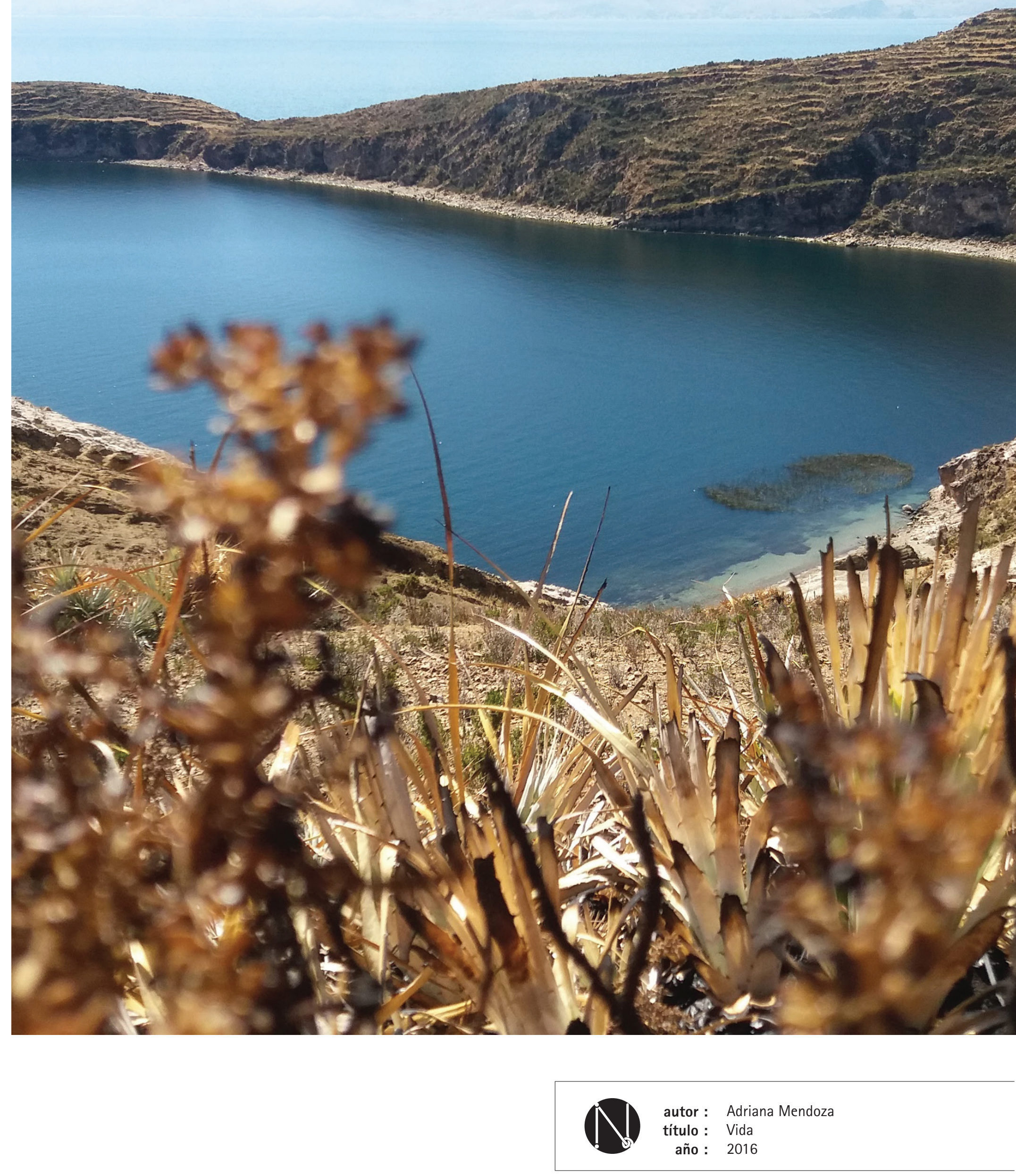

